NASA TN D-413

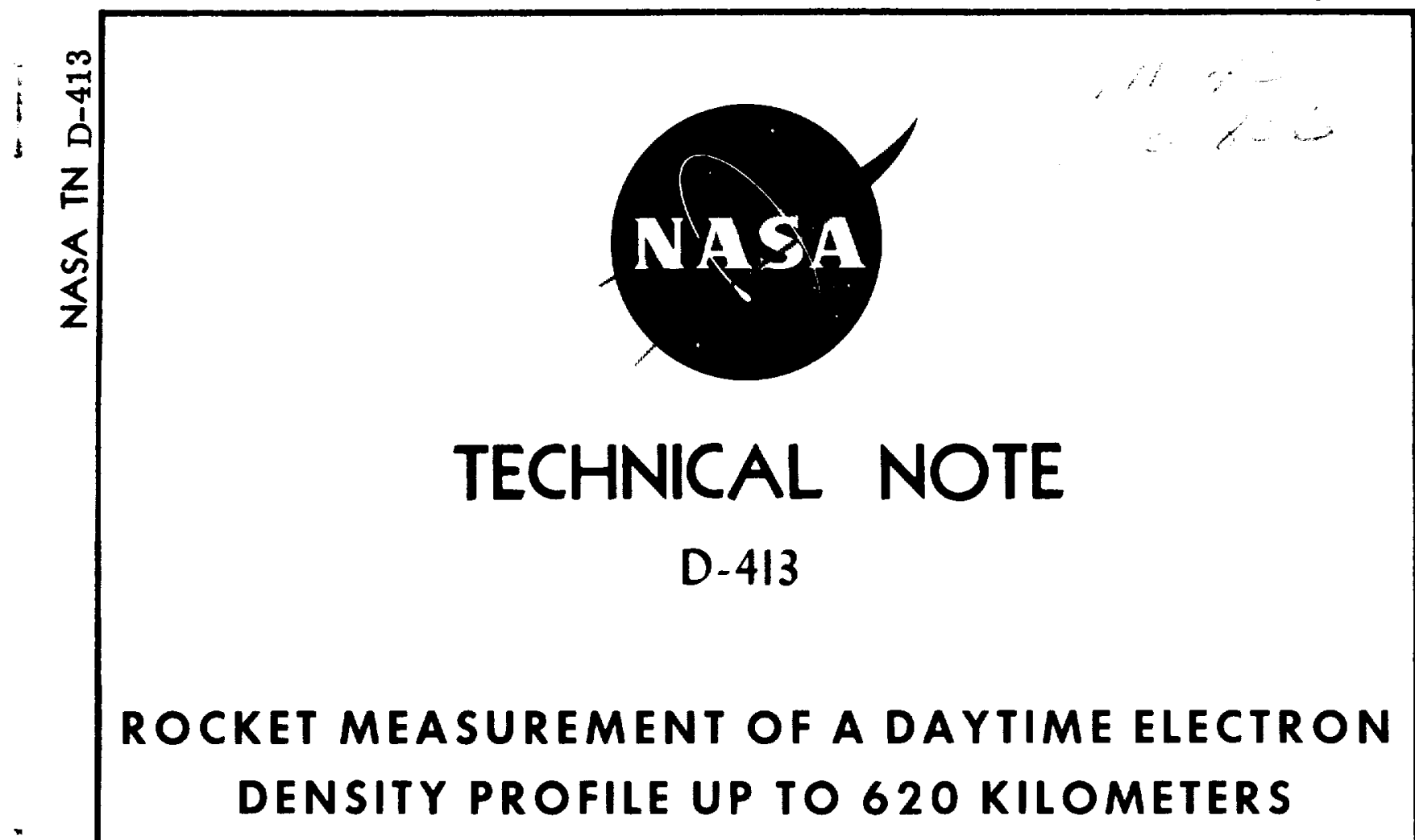

J. E. Jackson and S. J. Bauer

Goddard Space Flight Center

Greenbelt, Maryland

NATIONAL AERONAUTICS AND SPACE ADMINISTRATION WASHINGTON 


\section{ROCKET MEASUREMENT OF A DAYTIME ELECTRON DENSITY PROFILE UP TO 620 KILOMETERS}

by

J. E. Jackson and S. J. Bauer

Goddard Space Flight Center

SUMMARY

On April 27, 1961 at 1502 EST a four-stage research rocket was fired from Wallops Island, Virginia, to measure the ionospheric electron density distribution by means of Seddon's CW propagation technique. This experimental technique is based upon the dispersive Doppler effect measured at two harmonically related frequencies, in this case $f=12.267 \mathrm{Mc}$ and $6 \mathrm{f}=73.6 \mathrm{Mc}$. The electron density profile measured above the peak of the F2 region is representative of a diffusive-equilibrium distribution in an isothermal ionosphere having a temperature of $1640^{\circ} \pm 90^{\circ} \mathrm{K}$. This result, when compared with satellite and other data, indicates that the upper ionosphere is in thermodynamic equilibrum. 



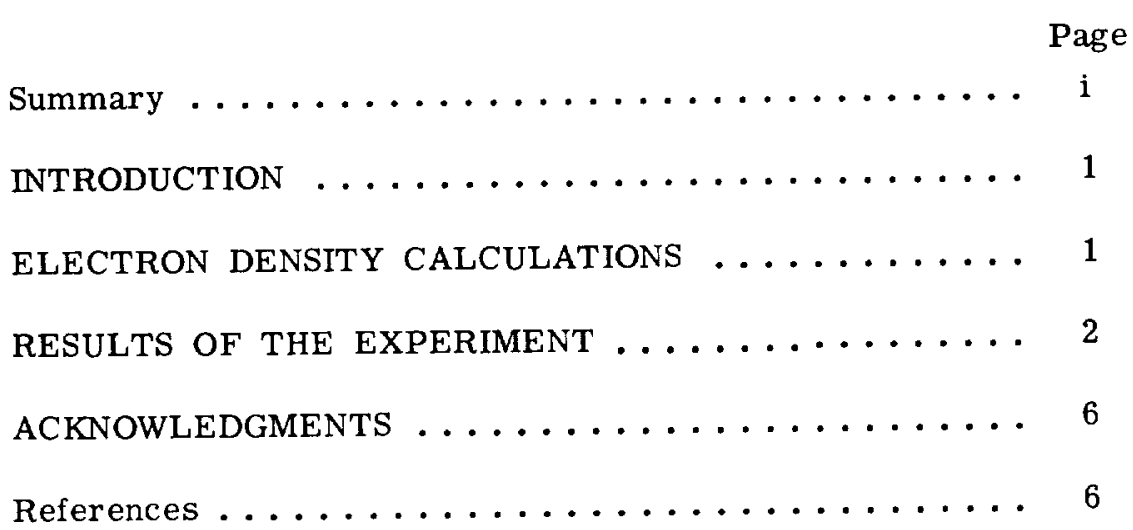




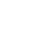




\title{
ROCKET MEASUREMENT OF A DAYTIME ELECTRON DENSITY PROFILE UP TO 620 KILOMETERS
}

\author{
by \\ J. E. Jackson and S. J. Bauer \\ Goddard Space Flight Center
}

\section{INTRODUCTION}

On April 27, 1961 a four-stage research rocket was fired from Wallops Island, Virginia, to measure the ionospheric electron density distribution by means of Seddon's $\mathrm{CW}$ propagation technique (Reference 1). This experimental technique is based upon the dispersive Doppler effect measured at two harmonically related frequencies, in this case $\mathrm{f}=12.267 \mathrm{Mc}$ and $6 \mathrm{f}=73.6 \mathrm{Mc}$. The quantities actually measured in the $\mathrm{CW}$ propagation experiment are the beat frequencies due to the difference between the received high and low frequency signals (the latter multiplied by the factor 6 at the ground) for the two magnetoionic components.

These beat frequencies can be expressed by

$$
(F B)_{0, x}=\frac{6 f}{c}\left[\left(n_{0, x}^{(h)}-n_{0, x}^{(\ell)}\right) \dot{r}+\int_{0}^{r} \frac{d}{d t}\left(n_{0, x}^{(h)}-n_{0, x}^{(l)}\right) d r\right] \pm \text { roll correction, }
$$

where $c$ is the velocity of light in vacuo; $n^{(h)}$ is the refractive index at the high frequency and $n^{(\ell)}$ that at the low frequency; the subscripts o and $x$ refer to the ordinary and extraordinary modes respectively; and $\dot{r}$ is the rocket velocity in the direction of the ray.

The first difference term in Equation 1 is a measure of the local electron density at the rocket, while the second term corrects for the variation of the electron density distribution along the ray path. For a quiet ionosphere, the second term depends mainly on the geometry of the trajectory.

\section{ELECTRON DENSITY CALCULATIONS}

The present analysis was based on the sum of the ordinary and extraordinary beat frequencies, which may be expressed: 


$$
F_{S}=\frac{6 f}{c} \dot{r}\left[\left(n_{0}{ }^{(h)}+n_{x}^{(h)}\right)-\left(n_{0}{ }^{(\ell)}+n_{x}^{(l)}\right)\right] .
$$

This sum has the advantage of being free of roll effects, since the individual ordinary and extraordinary beat frequencies have equal but opposite roll corrections. Furthermore the quantity $F_{S}$ is almost independent of the variation of the earth's magnetic field over the ranges of altitude and electron density covered by this experiment.

From $\mathrm{F}_{\mathrm{S}}$ an apparent electron density corresponding to

$$
N^{\prime}=\frac{1}{\Delta r}\left(\int_{0}^{P_{2}} N d r-\int_{0}^{P_{1}} N d r\right)
$$

can be obtained by means of the Appleton-Hartree formula together with trajectory information giving the radial velocity component.

The trajectory for this particular rocket flight is shown in Figure 1. As the result of the curvature of the trajectory, the electron density distribution along the ray path changes as the rocket moves from $P_{1}$ to $P_{2}$ (see the insert in Figure 1). Ground based soundings of the ionosphere obtained simultaneously at Wallops Island, Virginia, Patuxent River, Maryland, and Fort Belvoir, Virginia, showed that the ionosphere was very quiet during the rocket flight and that there were no significant horizontal gradients in the electron density. Thus, the actual electron densities $N$ were derived from the apparent densities $N^{\prime}$ by using the following correction procedure:

$$
N=N^{\prime}+\frac{\epsilon}{1-\epsilon}\left(N^{\prime}-\bar{v}\right)
$$

in which $\epsilon=(\mathrm{r} \dot{\theta} / \mathrm{r})$ tan $\theta_{\mathbf{r}}$, where $\theta$ is the zenith angle of the position vector at the receiving site and $\theta_{r}$ is that angle at the rocket; $r$ is the radial distance of the rocket with respect to the receiving site; and

$$
\overrightarrow{\mathrm{N}}=\frac{1}{\mathrm{r}} \int_{0}^{\mathrm{r}} \mathrm{N} \mathrm{dr}=\frac{1}{\mathrm{r}} \int_{0}^{\mathrm{r}} \mathrm{N}^{\prime} \mathrm{dr}
$$

\section{RESULTS OF THE EXPERIMENT}

In calculating $\overline{\mathrm{N}}$, the integration below $225 \mathrm{~km}$ was based on electron density data from ground based vertical-incidence soundings. The magnitude of the obliquity correction is indicated on the trajectory curve in Figure 1; it is seen that the maximum correction 


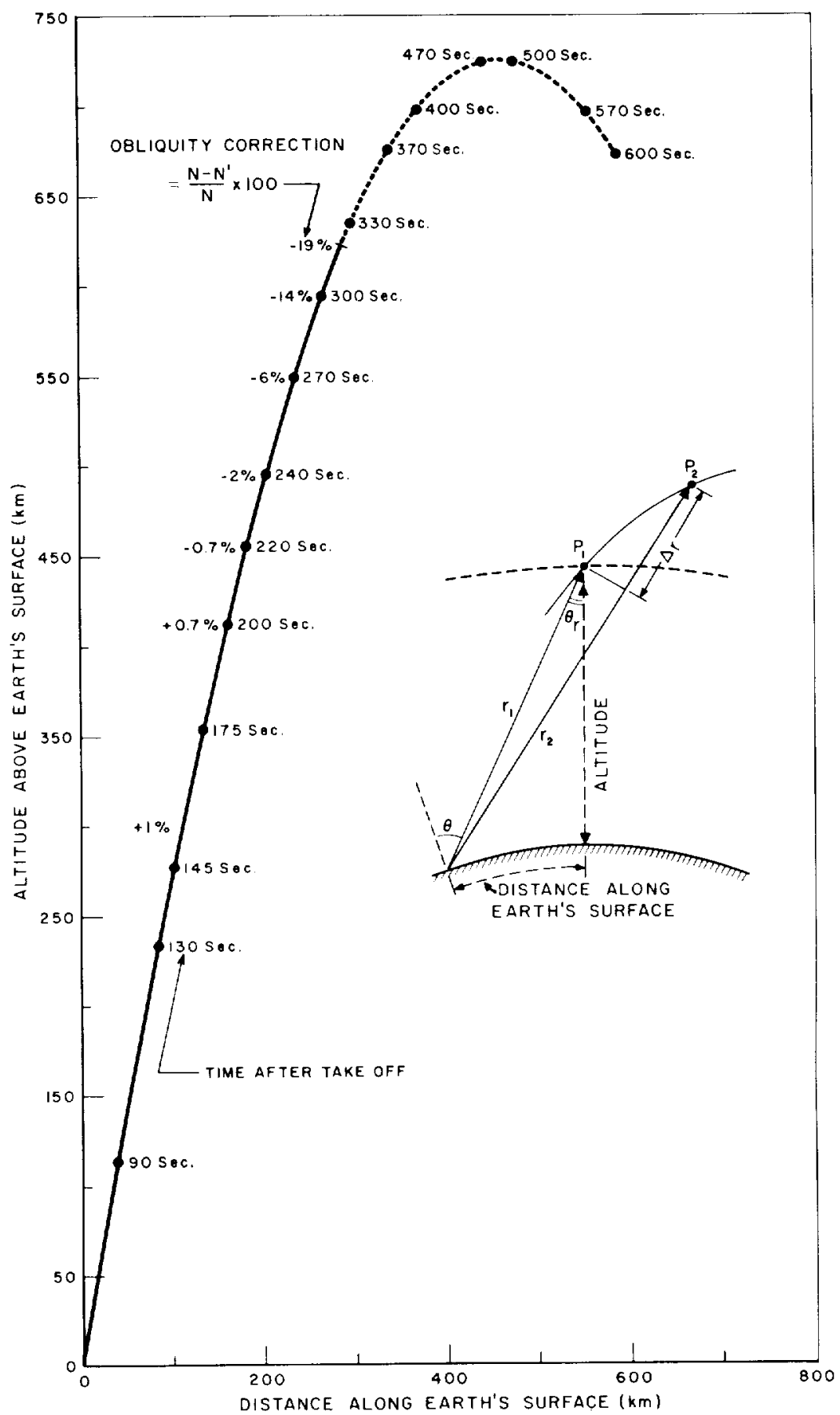

Figure 1 - Trajectory of NASA Rocket 8.10 fired from Wallops Island April 27, 1961 af 1502 EST 
(-19 percent) occurs at $620 \mathrm{~km}$, while below $400 \mathrm{~km}$ the correction is of the order of 1 percent.

Figure 2 shows the resulting electron densities up to an altitude of $620 \mathrm{~km}$. The measurements began at an altitude of $225 \mathrm{~km}$ after the ejection of the rocket nose cone and extension of the rocket borne transmitting antennas. The experimental points represent averages over a period of one second; they were read at approximately one-second intervals up to an altitude of about $320 \mathrm{~km}$, and at approximately 5 -second intervals for the remainder of the profile. The accuracy in reading the beat frequency records from which electron densities were calculated is of the order of 1 percent; the estimated accuracy of the trajectory determination is of the same order.

The maximum electron density as derived from the vertical incidence sounder at Wallops Island is seen to be in excellent agreement with the value derived from the rocket measurement (Figure 2). The electron density profile above the F2 peak exhibits a practically constant logarithmic slope which is representative of a diffusive-equilibrium distribution in an isothermal ionosphere. This slope yields a scale height for the electronion gas:

$$
H^{\prime}=\frac{k\left(T+T_{e}\right)}{m_{i} g}=200 \pm: 1 \mathrm{~km},
$$

where $\mathrm{k}$ is Boltzmann's constant, $\mathrm{T}$ is the ion (and neutral particle) temperature, $\mathrm{T}_{e}$ is the electron temperature, $m_{i}$ is the mean ionic mass, and $g$ is the acceleration of gravity. Assuming local thermodynamic equilibrium and a mean ionic mass corresponding to oxygen ions $\left(m_{i}=16\right)$, a constant gas temperature of $\mathrm{T}=1640 \pm 90^{\circ} \mathrm{K}$ is inferred for the altitude region between 350 and $600 \mathrm{~km}$. This temperatıre inferred from the daytime profile is in good agreement with daytime temperatures de 'ived from satellite density data, which also indicate appreciable diurnal and seasonal ternperature variations (References 2 and 3). Such a temperature variation is also apparent when the daytime (1502 EST) temperature of $1640^{\circ} \mathrm{K}$ is compared with an evening (20.44 EST) temperature of $1240^{\circ} \mathrm{K}$, inferred from a positive-ion density profile above the $\mathrm{F} 2$ peak, measured at Wallops Island in November 1960 (Reference 4).

The temperature inferred above is also in agreement with the daytime value of electron temperature $\left(1800^{\circ} \pm 300^{\circ} \mathrm{K}\right.$ at $\left.1700 \mathrm{EST}\right)$ directly meas.ured on the Explorer VIII satellite (Reference 5). The fact that this daytime temperature agrees with the neutral gas temperature derived from satellite density data as well as with the directly measured electron temperature is a good indication of thermodynamic equilibrium in the upper ionosphere. 


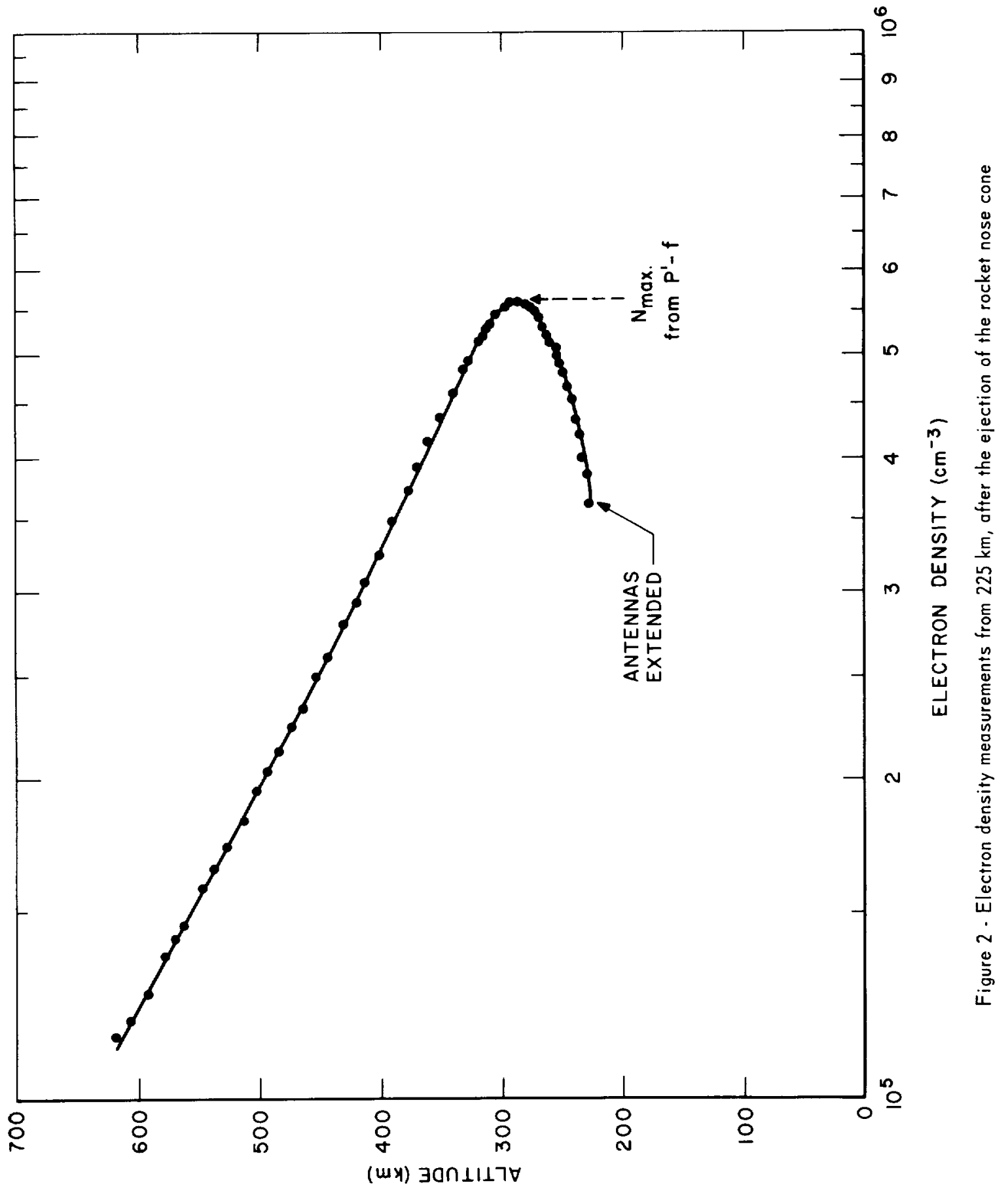




\section{ACKNOWLEDGMENTS}

The instrumentation used in this experiment was designed by Messrs. G. H. Spaid and J. R. Hagemeyer. The contributions of Mr. J. Carl Seddon in designing the system are gratefully acknowledged.

\section{REFERENCES}

1. Seddon, J. C., "Propagation Measurements in the Ionosphere with the Aid of Rockets," J. Geophys. Res. 58(3):323-335, September 1953

2. Kallmann-Bijl, H. K., "Daytime and Nighttime Atmospheric Properties Derived from Rocket and Satellite Observations," J. Geophys. Res. 66(3):787-795, March 1961

3. Martin, H. A., Neveling, W., Priester, W., and Roem $ə$ r, M., "Model of the Upper Atmosphere from $130 \mathrm{~km}$ through $1600 \mathrm{~km}$ Derived froln Satellite Observation," Proc. 2nd Internat. Space Science Sympos. sponsored by Ccmmittee on Space Research (COSPAR), Florence, Italy, April 13, 1961 (to be published)

4. Hanson, W. B., and McKibbin, D. D., "An Ion-Trap M sasurement of the Ion Concentration Profile Above the F2 Peak," J. Geophys. Res, 66(6):1667-1671, June 1961

5. Bourdeau, R. E., Donley, J. L., Serbu, G. P., and Wh pple, E. C. Jr., "Measurements of Sheath Currents and Equilibrium Potential on the lxplorer VIII Satellite," Proc. Amer. Astronaut. Soc. Sympos. March 17, 1961; also NASA Technical Note D-1064, 1961 


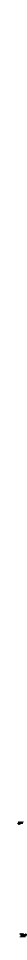




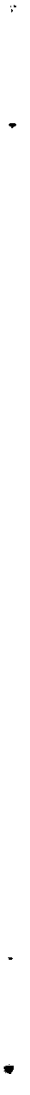

